\title{
E-knowledge Management in Public Administration: An Agenda for the Future
}

\author{
Ignace Snellen \\ Erasmus University, Postbox 1738, NL-3000 DR, Rotterdam, The Netherlands \\ snellen@fsw.eur.nl
}

\begin{abstract}
Knowledge Management has always been a constant concern in public administrations. Many ICT enabled applications of Knowledge Management have become available to support managers and street level bureaucrats with their policy development and policy implementation tasks. In a democratic constitutional state citizens are entitled, as well, to profit from the growing possibilities to influence policies and to monitor the performance of governments. It is time for a systematic development of an agenda of eKnowledge Management for citizens in the future information society.
\end{abstract}

\section{Introduction}

Knowledge Management (KM) always has been a constant concern within public administrations.

More so than in private enterprise. One of the reasons for this is that, at least in constitutional states, the equality before the law principle is adhered to. Equal cases have to be handled equally. This principle gives special importance to "precedence". A decision taken in a former case will normally be decisive for the outcome in a later similar case. To enable public officials to take former cases into account, public administrations have to store those cases into their memory. So, this knowledge about cases has to be assembled, stored, and made available, when it is necessary to do justice to the case at hand. The same reasons apply for the storage of jurisprudence in public memory systems.

Besides, public administrations function within a legal environment, in which not only the content of decisions has to be based upon legal rules and regulations, but in which also the way in which those decisions are reached have to answer to the principles of due process. Legal control of the procedures according to which the decisions are reached is not possible without the possibility to retrieve the factual procedures that were followed, and without the knowledge of the criteria that have to be applied. Thus, Knowledge Management is not only required to know which rules and regulations to apply, but also to be able to reconstruct afterwards whether the right procedures were followed.

In Germany an illuminating distinction is made between "Dienstwissen" and "Fachwissen", i.e. between the knowledge that is built up within public administration ("Dienst") about factual situations and the knowledge that is related to the professional execution of administrative tasks ("Fach"). Both kinds of knowledge are essential prerequisites for a democratic, and legally well functioning, public administration, and to attain effective and efficient policies.

The original version of this chapter was revised: The copyright line was incorrect. This has been corrected. The Erratum to this chapter is available at DOI: 10.1007/978-3-540-44836-5_33 
Weggeman makes a distinction between three dominant ways of operationalising Knowledge Management: 1) KM supported by ICTs, 2) KM through human talent development, and 3) KM through the design of a knowledge friendly organisation. In this paper the focus is upon the use of digital Information and Communication applications (ICTs) for different forms of Knowledge Management.

\section{A Knowledge Management Framework for Public Administration}

In this paper I will not make an inventory of all possible applications of Knowledge Management in public administration, but limit myself to applications of ICT on policy development and policy implementation as fields of Knowledge Management. The question I try and answer in this paper is, what agenda items could be raised to extend and improve the use of ICTs as instruments of Knowledge Management for policy development and policy implementation. Public managers, public servants and the citizens are seen as the three groups of possible stakeholders in the agenda items and as users of those ICTs.

The correctness or legality of the acts and activities of public authorities requires:

- a constitutive legal basis for the existence, the jurisdiction and the policy making of those authorities;

- a regulatory basis for their administrative decisions, their law maintenance and their inspection activities;

- a discretionary basis for their ex ante and ex post evaluations, their monitoring and their control..

Every public authority has to take care that all segments of the organisation are fully aware of those legal requirements, their content, and the possibilities and limitations they entail.

This a first dimension of Knowledge Management in public administration.

As far as the control activities with respect to public authorities are concerned, a distinction could be made between:

- democratic control by the media, interest groups, political parties and representative councils of the citizenry and the citizens themselves;

- political control by parliaments and other bodies of people's representation, to check whether the decisions of the legislature are implemented;

- legal control by courts, ombudsmen and other judicial bodies, of which the assigned function is, to judge the right rule-application by the administration;

- business control by managers, who are responsible for the "faits et gestes" of the employees as well as the clients of the organisation they manage;

- historical control by future generations against a common cultural background of a nation, a region, a city or a community.

This is a second dimension of Knowledge Management in public administration. 


\section{Leads for Knowledge Management in Policy Development and Policy Implementation}

Most steps in public policy development and policy implementation require knowledge imputs. It is a task of Knowledge Management to see to it that the requisite knowledge is available at the time and in the form, necessary to realise successful and legitimate policies.

For policy development and policy implementation, each, different points of contact for Knowledge Management can be explicited and possible applications of ICT to facilitate Knowledge Management indicated.

In this paper the following points of contact for Knowledge Mangement with respect to Policy Development and Policy Implementation are distinguished:

Knowledge Management requirements for Policy Development (PD)

PD 1. data, information and knowledge about (cumulative) problem situations of segments or categories of the population, that require action of the public authority. Datamining in statistical data repositories, analysis of the data created by "informating" (Zuboff 1988) and the development of so-called "profiles" of categories of a population are obvious methods to detect those problematic situations. Geographic Information Systems (GIS) may be strong tools to analyse and visualise the situation.

PD 2. insight in the causes of a problematic situation. The development of a causal "policy theory" may be supported by sophisticated ICT applications such as are used in social scientific research (SPSS). GISs may appear as strong analytical tools for the development of policy theories as well.

PD 3. feel for the most promising "intervention variables" to be derived from the policy theory. Simulation games may facilitate to get a feel for the likely candidate intervention variables, and the facility of an ICT equiped "decision room" may help to test the acceptability of the choice of interventions with the policy partners.

PD 4. the effectiveness of possible policy instruments has to be assesssed, apart from the choice of the intervention variables. In principle three kinds of policy instruments are to be considered: financial instruments, communicative instruments and legal instruments. The effectiveness of all three instruments could profit from the application of ICTs. Websites are an obvious example of the facilitation of communicative instruments through ICT. Textblocks (Snellen 2001) may facilitate legal instruments and spreadsheets financial instruments.

PD 5. ex ante evaluations, and the estimation of probable policy effects, are furthered by systematic feedback from former policies, that may become facilitated by ICT applications such as datamining, spreadsheets, and GISs.

PD 6. ex post evaluations and the determination of the outputs and outcomes of policies are greatly helped by the development of performance indicators and benchmarking.

Knowledge management requirements for Policy Implementation (PI)

PI 1. Information on the workflow and its different steps. Through electronic workflow management systems the public servants and their managers may keep an eye on the task sequences, on the steps that are still ahead, and on deadlines that have to be met.

PI 2. Information on the procedures which are prescribed in all kinds of general and specific legal rules and regulations, and in organisational policy documents. All 
kinds of software ( such as advisory systems, expert systems and processing systems) have been developed to assist the public servant in reaching a correct decision.

PI 3. internal information about clients, based upon former interactions with those clients. Electronic files and databases, shared between the departments of an organisation, are playing an ever growing role in contacts of the officials with the clients.

PI 4. external information about clients, provided by outside organisations via the intermediary of an information office, which verifies the information the client is giving. In a former presentation (Snellen 2001) I refered to the role of the Dutch Routing Institute for (inter)National Information Streams (RINIS) with respect to front end verification.

PI 5. information about the general circumstances, in which a policy has to be made a success, and a client has to be supported, such as the employment situation, the level of schooling, or the kind of organisational support, that is available. Geographic Information Systems (GIS) may play an important role in this respect.

PI 6. information about the legal situation of the clients and their entitlement to permits, support or subsistance, as has to be retrieved from laws and regulations. Advisory systems, Expert (support) systems and Processing systems are the kind of decision support tools that are used for these purposes.

PI 7. management information about the workload, and other working conditions, of the employees of the public organisation. Next to workflow management systems, different kinds of ICT tools for Human Resource Management, such as absenteism registration, labour turnover statistics, exit interviews et cetera, are applied for this purpose.

PI 8. management information about the correctness as well as the average content of the decisions of the employees. Relational databases can be instrumental to give management a daily, weekly or other periodical overview of the results per employee. ICT applications in Call Centers are notorious in this respect.

PI 9. management information about the organisational consequences - a.o. in terms of personnel or finances - of the decisions that are being taken. The feedback reporting time about the consequences of the organisational activities is becoming ever shorter. Spreadsheets are a common tool to get in advance a systematic overview on those consequences.

PI 10. management information about the consequences of the decisions for tasks and activities down the interorganisational chain of services and provisions. Common approaches like sharing of databases and solutions like the above mentioned RINIS make it possible to take the repercussions for other public organisations, down the value chain of services or provisions, into account. Apart from that, applications of Computer Supported Cooperative Work $(C S C W)$ may come into play.

\section{ICTs in E-knowledge Management for Public Policy}

The overriding impression is that the citizen is an underprivileged user of eKnowledge Management (e-K.M.), while mangement and officials are ever better served. Management and public officials are well served by a whole array of eKnowledge Management tools, but that the citizen is almost completely neglected. However, a viable agenda for the future to serve the citizen with e-Knowledge tools in public administration could be as follows: 


\section{Geographic Information Systems.}

As far as policy development is concerned, the citizen could be served by Geographic Information Systems (GIS). GISs make it possible to combine geodata about physical environments, in which people live, with statistical data about their social situation such as levels of schooling, criminality, unemployment, health, life expectancy and so on. These data are essential imputs in policy development. A coupling of the geodata and the statistical data with the administrative data, that are created during policy implementation, are of the utmost importance for a possible democratic influence by the citizens. (Snellen 2001) The administrative data, generated within public administrations during policy implementation, give evidence about what public officials and their managers in fact are performing for a group or a sector in society. Comparison of the geodata, the statistical and the administrative data with the help of GIS makes it crystal-clear whether the public authority has been responsive to the (accumulation of) problems in the area covered by the GIS.

"A condition for effective influence by citizens and their interest groups is access to the data that are available within the public service. In most countries freedom of information is rather limited. It may be restricted to documents on which a policy is based. As policy documents, they will generally be fashioned to the knowledge interest of the policy-maker." " ....access to the (raw) data available within the public domain is for the citizen - especially in the information society - much more important than the information in policy documents, which is edited with a certain purpose or view-point in mind. However, opposition to the transparancy of the workings of politics and public bureaucracies is massive." (Snellen 2002)

During the implementation of policies GISs can be helpful in demonstrating in what kind of environment they have to be made a success. Citizens and their organisations may use the GISs to improve the adequacy of the policies concerned.

\section{Software programs.}

Workflow system programs are in use to guide the officials through the bureaucratic maze of the case handling and to give their managers an overview of the caseload of each employee, of the kind of decisions each of them is taking, and of the progress of the activities. It would be worthwhile to enable the citizen to have, as well, a view on the progress of his/her case. Reference can be made to the postal services like UPS that give their clients insight in the handling process and give them an exact indication of the location of their mail. Comparable programs would be feasible all over the public administration.

Another program that deserves our attention is the creation of a personal data safe at the disposition of the citizen, in which all the personal data of the citizen - as far as he/she likes it - are stored. If every authority, that uses those personal data, is obliged to give notice of the use to the personal data safe, the citizen keeps a complete and upto-date overview on his/her own privacy.

A third move in terms of software programs, that might substantially improve the situation of the citizens in their contacts with the authorities, would be if the advisory systems and expert systems that are developed as decision support tools for the officials are made available to the clients. This would enable clients to try and find a "winning profile" for the entitlement of a subsidy or any other kind of support. Especially underprivileged clients need this kind of help. Software programs are also more and more becoming into use to help the official to find the right (and best immunized) justification of the administrative decisions he/she takes. So-called "text building blocks", pre-fabricated motivations of positive or negative administrative 
decisions, are developed to assist the official in the decision making process. The more this decision behaviour of the official has become routinized the more important it is for the citizen to have access to the software programs by which the justifications of the administrative decisions are made. This kind of e-Knowledge Management for the citizen will put both public authorities and citizens on a more equal footing.

And finally, software programs that provide citizens with scores as to performance indicators through monitoring and benchmarks enable them to keep horizontal overview and guidance on the efforts and results of governmental policies.

\section{Conclusion}

In a modern constitutional state e-Knowledge Management is playing a major role in the management and functioning of public administrations. Especially public managers and public officials are supported by ICT applications for e-Knowledge Management. Almost every step in policy development and policy implementation is guided by e-Knowledge Management and the number of applications is still growing.

Citizens, however, have to manage almost without assistence in this respect, although the possibilities to strengthen their position in interactive policy making, monitoring and control are growing. It is time for a systematic development of an agenda of e-Knowledge Management for citizens in the fuuture information society.

\section{References}

1. Snellen, Ignace: ICTs, Bureaucracies, and the Future of Democracy. Communications of the ACM, januari 2001/Vol.44, No. 1, p. 45

2. Snellen, Ignace: Entrapments in Knowledge Management: The fate of street level bureaucrats. In: Wimmer Maria A. (Ed.): Knowledge Management in e-Government. KMGov-2002. Universitätsverlag Rudolf Trauner, Laxenburg.

3. Snellen, Ignace: Electronic governance: implications for citizens, politicians and public servants. International Review of Administrative Sciences, Vol. 68, No. 2, June 2002

4. Snellen, Ignace: E-government and E-democracy: Practices and Problems. In; Manolopoulos Y. and Evripidou S. (Eds): 8th Panhellenic Conference in Informatics. Proceedings Vol. 2, Nicosia, November 2001

5. Weggeman, Mathieu: Kennismanagement: leidinggeven aan kenniswerkers. In: Van Duivenboden H. a.o. (Eds): Kennismanagement in de publieke sector. Elsevier bedrijfsinformatie bv, 'sGravenhage, 1999, p.45-63.

6. Zuboff, S.: In the Age of the Smart Machine. Basic Books 1988. 